\title{
Festa e Perfomance em Espaço Público: tomar a rua! ${ }^{1}$
}

\author{
Paulo Raposo \\ IUL/CRIA, Lisboa - Portugal \\ E-mail:pjp.raposo@gmail.com
}




\section{Resumo}

África, Europa, Ásia, Américas, um rastilho incendiário espalha-se pelas praças, pelas ruas, pelos bairros reclamando o espaço público. Tomar a praça torna-se um movimento performativo de intensidade nova em um plano que redefine escalas políticas globais, nacionais e locais. Explora-se aqui neste artigo, por via do caráter festivo de perfomances políticas em espaço público, os ambíguos sentidos e desígnios para estes novos espaços, de democratização e de indignação que se espalham pelo mundo. Abrindo a rua, tomando a praça, são condições para que movimentos massivos ou pequenos grupos tomem a voz, expressem a indignação, ensaiem a participação coletiva, colaborativa ou até mesmo ações radicais; estes movimentos sociais contemporâneos parecem explorar a ocupação de espaços públicos, como perfomance e usando mídias radicais, em resposta aos processos de exclusão, de silenciamento e de invisibilidade em curso na sociedade contemporânea.

Palavras-chave: Perfomance. Movimentos Sociais. Espaço Público. Ocupação.

\section{Abstract}

From Africa, Europe, Asia, America, merge a fuse spread by squares, streets, and districts reclaiming public space. Take the square becomes a performative movement of new intensity in a way that redefines global, national and local political scales. This article explores, through the festive character of political perfomances in public space, the ambiguous senses and thoughts to these new spaces of democracy and outrage spread all around the world. Opening the street, taking the square, are conditions for massive movements or small groups to take the voice, to express the indignation, and to rehearse the collective and collaborative participation or even radical actions; this contemporary social movements seems to explore the occupation of public spaces as perfomance using radical media skills, as an answer to the contemporary processes of exclusion, silencing or invisibility.

Keywords: Perfomance. Social Movements. Public Space. Occupy. 


\section{Introdução}

ueria começar por recordar um velho e brilhante texto de Roland Barthes da sua obra Mytologiques que discorre sobre o carácter performativo de uma inundação em Paris:

Apesar dos transtornos ou das infelicidades que possa ter trazido aos milhares de franceses, a inundação de janeiro de 1955 participou da Festa, mais do que da catástrofe. De início deslocou certos objetos, reavivou a percepção do mundo, introduzindo pontos insólitos e, contudo, explicáveis: viram-se carros reduzidos a tetos, lampiões de rua truncados, apenas a cabeça sobrenadando como um nenúfar, casas cortadas como cubos de crianças, um gato preso diversos dias sobre uma árvore. [...] A enchente subverteu a ótica cotidiana, sem, contudo, desviá-la para o fantástico; os objetos foram parcialmente obliterados, não deformados: o espetáculo foi singular, mas razoável. Toda ruptura um pouco ampla do cotidiano dá início à Festa: ora, a enchente não apenas escolheu e deslocou certos objetos, ela subverteu a própria cenestesia da paisagem, a organização ancestral dos horizontes [...]. (Barthes, 2009, p. 62)

Quero explorar aqui, por via do carácter festivo da perfomance em espaço público, os ambíguos sentidos e desígnios para "novos espaços" de democratização e de indignação que se multiplicaram pelo mundo a partir de 2009, acompanhando o terramoto financeiro do capitalismo moderno e acentuando a chamada crise da democracia. Por África, Europa, Ásia, Américas, um rastilho incendiário se espalhou pelas praças, pelas ruas, pelos bairros reclamando o espaço público. Tomar a rua tornou-se um movimento performativo de intensidade nova em um plano que se refina e se intersecta em escalas globais, nacionais e 
locais, usando meios de comunicação e tecnologias de agit-prop da era digital. John Downing (2002) havia explicitado já as características de uma mídia radical em processos de transformação e de mudança social que expandia as potencialidades de os movimentos sociais partilharem e trocarem informações para além do espaço que lhes era reservado pelas mídias convencionais:

Esse tipo de mídia (radical) hoje vai além do uso das tecnologias, ela inclui uma gama de atividades como o teatro de rua, a dança entre outras manifestações comunicacionais. [...] A mídia radical não está interessada na audiência por ser domesticada pelo mercado a ser estática e efêmera. [...] A mídia radical propõe a seu público o debate, a crítica e a ação. (Downing, 2002, p. $39-42)$

Libertando a rua, ocupando a praça, movimentos massivos ou pequenos grupos ganham voz, expressam a indignação, ensaiam a participação coletiva, colaborativa, contextualizada ou até mesmo radicalizante e interventiva, explorando a vivência performativa de espaços públicos em resposta aos processos de exclusão, silenciamento e invisibilidade em curso nas sociedades contemporâneas.

Arturo Escobar, na última década do século XX, havia já sublinhado a relevância dos movimentos sociais na teoria social para um melhor entendimento da modernidade:

Social movements, it is argued, emerged out of the crisis of modernity; they orient themselves towards the constitution of new orders, and embody a new understanding of politics and social life itself. They result in the formation of novel collective identities which foster social and cultural forms of relating and solidarity to response to the crises of meanings and economies that the world faces today. [...]This relevance derives from the basic fact that today's social movements are seen not only as political struggles in pursuit of socio-economic goals but also, and essentially, as cultural struggles. (Escobar, 1992, p. 396-397)

Alain Touraine havia também reforçado a ideia de que a emergência dos movimentos sociais no século XX não era tanto um evento 
dramático, mas antes o resultado da perfomance que a sociedade faz sobre si mesma, e o resultado dessa ação performativa é basicamente a luta sobre o controlo da historicidade - i.e., o conjunto de modelos culturais que governam as práticas sociais e estão incorporadas em modelos de conhecimento, econômicos e éticos (Touraine, 1996). Touraine destacou, porém, diferenças entre mobilização social no então chamado Terceiro Mundo onde se verificavam, em seu entender, sobretudo lutas que procuravam mudanças sociais e desenvolvimento e os movimentos sociais nas sociedades pós-industriais que lutavam agora pelo controlo da historicidade. Essa distinção problemática de Touraine assenta numa visão etnocêntrica da história retirando capacidade de agência aos países periféricos dos centros pós-indústriais. Para além das críticas da teoria social que se lhe seguiram, a contemporaneidade poderá estar a demonstrar justamente que aquela visão é algo redutora, na medida em que a capacidade das margens (do mundo global) produzirem e criarem a sua própria história é claramente evidente².

\section{As Praças da Indignação: das imolações solitárias às performaces políticas assembleares}

Quando subitamente ${ }^{3}$ no dia 25 de janeiro de 2011 e durante 18 dias consecutivos na Praça Tahrir no Egipto se deu o despertar da chamada revolução ou primavera árabe, assistimos de algum modo à transformação daquele espaço público numa expressão coletiva inimaginável. O quadro era, todavia, altamente tensional entre aqueles que se manifestavam, os aparelhos repressivos do Estado (polícia e exército), as redes sociais que constantemente confundiam estes últimos com mobilizações e ações constantes e Mubarak, o presidente e símbolo da ditadura que os manifestantes desejavam depor.

Curiosamente o rastilho desse movimento político de protestos no mundo árabe tinha sido já iniciado na Tunísia quando um comerciante de frutas e legumes de 23 anos, Mohamed Bouazizi, se imolou pelo fogo em Ben Aros a 17 de dezembro de 2010, junto ao governo local depois de uma longa disputa sobre a eventual ilegalidade da sua atividade. Após 18 dias veio a falecer gerando em seguida uma onda 
de protestos na Tunísia que vieram a resultar na queda do regime de Ben Ali, após 23 anos de poder.

Entretanto, em Nouakchott, a 17 de janeiro de 2011, Yacoub Ould Dahoud, de 43 anos, estacionou o automóvel, em frente ao Senado e à Presidência da República da Mauritânia, e imolou-se também no interior do veículo, depois de avisar jornalistas de que ia fazê-lo por estar descontente com o regime.

Esses atos isolados, tão simbólicos quanto trágicos, percorreram rapidamente o mundo árabe e espoletaram uma vaga de protestos contra regimes diversos ali instalados. Uma diferença estratégica, todavia, fez-se notar. Da dimensão performativa de um ato isolado assistiu-se ao florescimento de movimentos de massas, de multidões que ocupavam praças, junto a parlamentos, instituições de poder ou monumentos históricos.

A Praça Tahrir, conhecida pelo seu potencial turístico, mas também como símbolo da revolução republicana do Egito (1952), estava agora profundamente alterada nos seus usos cotidianos e, sobretudo, na organização da sua paisagem. A imensa presença de pessoas empunhando bandeiras, cartazes, o Alcorão, mas também celulares e máquinas fotográficas digitais, bem como uma nova cenografia daquele espaço repleto de mantas, tendas, cadeiras, mas também tanques e carros policiais, eram a marca visível e pictórica do descontentamento e do conflito. O trânsito encerrado e o "acampamento" em vigília permanente de centenas ou mesmo milhares de pessoas durante aqueles dias de insurgimento, permitiram também dar continuidade e perenidade ao protesto que finalmente logrou alcançar o seu objetivo mais permente: a destituição do presidente e do seu governo. E, dessa forma, essa ocupação transgressora do espaço público fez-se, em meu entender, através de uma evidente narrativa performática que resgatou - ainda que temporariamente - a esfera pública da ação política de novo para a rua, para a praça.

Obviamente, esses movimentos sociais em espaço público, mais ou menos espontâneos, não são casos isolados na história. Aquilo a que hoje se chama manifestações políticas em espaço público poderá ter o seu precedente longínquo na ideia de praça pública grega, ou 
Ágora, o lugar onde os cidadãos se encontravam regularmente para discutir o governo da cidade. Ou seja, lugares de copresença assembliária, limitados e sem muitos participantes, nem grande mediação como as que entusiasmaram Rosseau a propósito das assembleias suíças - "Landsgemeinde" que, aliás, continuam ainda hoje a se realizar em algumas comunidades daquele país - ou as que foram estudados pelo politólogo Alexis de Tocqueville para o caso das Townships americanas, ou ainda para o caso das famosas Sections no período revolucionário em França (1789-1793). Mas outras contaminações dessas manifestações contemporâneas podem decorrer também das mobilizações no século XX associadas à luta pelos direitos cívicos nos Estados Unidos, aos movimentos feministas, e maio de 1968 em França, à Primavera de Praga, em 25 de abril em Portugal, aos protestos da Plaza de Mayo em Buenos Aires ou de Tianamen em Pequim, aos protestos antiglobalização ou ambientalistas, às Marchas dos Sem-Terra, entre muitos outros. Todavia, tal como Gohen (2011) sublinha, existem novas condições em jogo no campo de atuação política dos chamados novíssimos movimentos sociais:

$\mathrm{Na}$ atualidade, os principais movimentos sociais atuam por meio de redes sociais, locais, regionais, nacionais e internacionais ou transnacionais, e utilizam-se muito dos novos meios de comunicação e informação, como a internet. Por isso, exercitam o que Habermas denominou de "o agir comunicativo". A criação e o desenvolvimento de novos saberes, na atualidade, são também produtos dessa comunicabilidade. (Gohen, 2011, p. 335-336)

Entretanto, o filósofo espanhol Daniel Innerarity (2010) assinala que o modelo de espaço público pré-moderno é diferente do modelo de esfera pública moderna que através da emergência da imprensa e de novos meios de comunicação se abstrai das assembleias concretas. E, acrescentando, seguindo a análise de Habermas, denota que na modernidade o modelo ocidental de espaço público acaba por se constituir em redor de instituições democráticas representativas, frequentemente também responsáveis pela sua "refeudalização" burocrática (Habermas, 1962). Já, Hannah Arendt, na sua obra The Human Condition (1958), havia também comentado criticamente a sua decadência, 
decorrente da usurpação do espaço público da discussão política pela irrupção do social - i.e., um mundo do trabalho e das necessidades no qual os seres humanos em vez de discutirem e agirem se alienavam como meros automatismos de uma sociedade da produção e do consumo. Innerarity (2010, p. 15) explicita que "[...] (s)em espaço público, em sentido estrito, o poder é entendido como dominação, o estado como instância das regulações sociais e a opinião pública como lugar das manipulações dos meios de comunicação social".

E, este é, de alguma forma, o contexto em que justamente esses processos de mobilização de massas, mais ou menos espontâneos, têm vindo a espoletar na atualidade.

Alberto Merlucci (apud Escobar, 1992) assinala justamente certa propensão profética dos movimentos sociais. Esses movimentos anunciam à sociedade que um problema fundamental existe em uma dada área e tornam-se, dessa forma, uma espécie de nova mídia. Emergem da experiência cotidiana sob as condições de dominação e devem ser entendidos sob essa condição subordinada de background cultural. Os movimentos sociais trazem consigo, portanto, novas práticas sociais operando em parte através da constituição de espaços para a criação de novos significados. Esses significados eliciam e articulam dimensões económicas, políticas e sociais no interior do campo cultural. E, como Escobar (1992) afirma, os movimentos sociais são as arenas adequadas para explorar e explicitar as interrelações entre vida cotidiana, democracia, Estado e a redefinição da prática política, sob a lupa da tensionalidade das relações de poder e de dominação que, simultaneamente, regulam e são objecto de reapropriação pelos sujeitos na sua cotidianidade.

Em Portugal, poucos meses depois da chamada Revolução do Jasmim tunisina, a 12 março 2011, uma manifestação de enormes proporções realizou-se sob o chamado de "um pequeno grupo de jovens activistas" que decidiram lançar um apelo nas redes sociais para juntar nas ruas a população descontente com a enorme precarização das condições de vida e com as medidas de austeridade impostas pelo governo (socialista) de então.

A manifestação ficou conhecida como o protesto da geração "à rasca" - termo que designa em português mais coloquial: aflito, desfa- 
vorecido, precarizado ${ }^{4}$. A conjuntura política do momento foi altamente propícia para a mobilização espontânea de milhares de pessoas que, nesse dia, de forma transversal em termos geracionais, profissionais, culturais e de classe, vieram a produzir uma das maiores manifestação de sempre no Portugal pós-ditadura, com mais de 300 mil pessoas a se manifestarem em diversas cidades de todo o país, atingindo as 200 mil em Lisboa. Esse foi, aliás, um dos rastilhos para a queda do governo um ano depois, em eleições antecipadas, mas foi, sobretudo, um importante contributo para o (re)nascimento dos movimentos sociais e de formas de protesto singulares em Portugal que se haviam tornado algo penumbrosas desde a entrada do país na Comunidade Europeia (1986).

Mas aqui teremos de dar entrada a outro contexto de protesto social de dimensões inesperadas: o movimento dos indignados em Espanha, depois também conhecido por Democracia Real Ya! ou por 15M. O movimento nasceu em 15 de maio de 2011 quando em Madrid alguns manifestantes decidiram acampar em plena Plaza Sol tendo sido violentamente reprimidos pelas forças policiais. De seguida, em cerca de 50 cidades de Espanha, vários milhares de pessoas (sobretudo jovens precários, desempregados, estudantes ou licenciados, mas depois também cidadãs e cidadãos anônimos de todas as idades e de várias condições econômicas) saíram às ruas sob o lema de "democracía real ya!"'5 - uma plataforma cívica, criada nas redes sociais e na internet, de movimentos sociais, associações, centros sociais e cidadãos anônimos que se mostravam indignados com o estado da democracia e com a crise financeira generalizada em toda a Europa. Curiosamente, esse movimento também se desenvolveu nas vésperas das eleições e pretendia se constituir como uma alternativa democrática à estrutura tradicional de partidos e sindicatos, cuja mensagem se sintetizou na palavra de ordem mais ouvida nas manifestações: No somos mercancia en manos de políticos y banqueiros! O que decorria deste processo de mobilização massiva estava muito centrado na criação de locais de discussão e decisão política alternativos aos tradicionais parlamentos e mesas de negociação sindical e partidária.

O elemento que gostaria de destacar nesse contexto diz respeito à dimensão assembliária de rua (ou de praça) e de bairro que cresceu 
exponencialmente no contexto espanhol como enfoque central do movimento. Diariamente ou em datas regulares, grupos de pessoas se reuniam no espaço público procurando pensar política em conjunto, criando regras de comunicação, processos de discussão e de decisão, baseados num certo consenso coletivo, na horizontalidade e na ausência de lideranças ou representantes. Esses processos democráticos de discussão pública estão obviamente mais permeáveis a resultados tanto abertos quanto incertos. Quando a esfera pública se torna o espaço onde os cidadãos podem convencer e ser convencidos ou amadurecer em conjunto as suas opiniões, como esse modelo assembliário se propôs realizar, nessa altura, a política parece se tornar um processo criativo que releva do âmbito da surpresa e da aprendizagem colectiva. A incerteza é, aparentemente, um indicador da qualidade dos espaços democráticos (Innerarity, 2010) que curiosamente tem sido esvaziada da dinâmica da discussão política confinada aos parlamentos, às "salas fechadas" ou aos debates mediáticos (sempre povoados de especialistas e comentadores). E, assim, essas assembleias horizontais viraram perfomances políticas em si mesmas onde narrativas diversas eram postas em debate e, por consequência, se tornavam elas mesmas ações e não apenas discursos.

As discussões sobre bem comum, interesse coletivo e a chamada "voz popular" parecem ter ficado reduzidas, nos espaços institucionais, a uma linguagem sem surpresa, a uma retórica demasiadamente previsível e pouco agregadora e, sobretudo, a um enorme distanciamento entre representantes e representados. Esse (novo) espaço de discussão política, construído pelas vozes sucessivas de pessoas anônimas, em contrapartida, procurava pela discussão gerir a diferença, a heterogeneidade e os interesses pessoais e coletivos (e até as emoções ou os relatos biográficos). A criação dessas assembleias no espaço público tem um valor democrático acrescido porque não é simplesmente o local onde todos têm o direito de defender seus desejos ou suas convicções, mas porque os colocam efectivamente em jogo no seio de um debate alargado - e de alguma forma, podem ser pensadas pelo enquadre teórico das existênciais ou espontâneas communitas desenvolvido por Victor Turner (1969). 
Embora se possa imaginar, num certo sentido turneriano, essas reuniões como lugares de liminaridade social (betwixt and between) provocados pela inversão, suspensão ou subversão dos significados e papéis simbólicos cotidianos dados a espaços, insígnias, estatutos, posições, idade, sexo, ou de qualquer outra demarcação entre sujeitos e que definem a emergência, justaposta ou alternada, de estruturas e antiestruturas (ou communitas), porém, esta oscilação opositiva que Turner sublinha pode ser demasaido limitadora e simultaneamente omissa para a caracterização destas perfomances políticas em espaço público. O que julgo ter observado nessas assembleias não foi propriamente a mera criação de uma homogenização de cidadania (tornada em "performers rituais") em suspensão dos seus papéis tradicionais na coletividade, foi antes, como sugeriu Richard Schechner (1995) no seu ensaio sobre a rua como palco, em uma espécie de flerte com a possibilidade de improvisação e complementarmente com a criação em processo de regras para o jogo. Se, como refere Schechner, existe uma longa tradição de construir grandes monumentos especificamente para apresentar perfomances - arenas, estádios e teatros - dos quais muitas vezes se constrói a ação política, existe também uma longa história de perfomances não oficiais "tomando o lugar" em locais que não foram arquitectonicamente imaginados como teatros. A perfomance art constitui-se, como movimento de vanguarda, a partir grosso modo dos anos 1970, digamos assim, nesse abuso simbólico, e, de algum modo, também essas perfomances políticas contemporâneas são abusos simbólicos das estruturas oficiais do diálogo político - os parlamentos e os gabinetes governativos. Resta saber em que medida essas convulsões sociais contemporâneas são mais da ordem do carnavalesco ou do revolucionário, ou seja, são mudanças temporárias ou perenes. (Schechner, 1995, p. 45)

Nas assembleias populares da Praça do Rossio em Lisboa - de que fui observador e participante desde 20 de maio de 2011 até ao seu desaparecimento alguns meses depois - algumas temáticas, aparentemente irrelevantes, eram debatidas calorosa e exaustivamente até gerarem algum consenso - como no caso do uso do x, do@ou do a/o para designações de gênero; ou como no caso do tipo de votação/ 
decisão ou no modo de funcionamento das assembleias. Tratava-se, portanto, de criativamente se estabelecerem os limites e as regras da discussão democrática fora de um circuito institucional e convencional onde o cidadão comum é fundamentalmente um espectador passivo, sempre sujeito à imprevisibilidade e ao improviso de cada assembleia.

\section{A Tensionalidade Performática em Espaço Público: a luta por um discurso entre a vivência e a desobediência}

A discussão em público que esses movimentos estão procurando realizar em tantas praças europeias tem sido referida por alguns como um cenário tumultuoso, perturbador e ameaçador - sobretudo pelos governos, pelas mídias mainstream e por setores das classes parlamentares - e por outros como refrescante, solidário, participativo e horizontal. Nesses eventos públicos, para além das intervenções cidadãs, dos discursos e leituras de manifestos, estão presentes muitos aspectos performáticos relevantes, chegando mesmo a ser constituída uma linguagem gestual nas assembleias da Puerta del Sol (Madrid) que acabou se espalhando a outros lugares (ou no caso do microfone humano no movimento Occupy Wall Street nos Estados Unidos). Essa performatividade cresce num roteiro simultâneamente festivo e de desobediência civil, ou seja, por um lado paradas, marchas, ações diretas ou outros eventos de rua são marcados por dimensões carnavalescas - música, máscaras, cartazes e palavras não previstas, guiões caóticos de protesto, ocupações de espaços imprevistas, erotização e exibição de afectos, comensalidade - e por outro por recurso a confrontos pacíficos (em quase todos os casos) ou violentos com as autoridades policiais (caso da Grécia terá sido o mais sangrento). Ressalve-se a este respeito a importante dimensão performativa que envolveu as chamadas "acampadas" - ou seja, acampamentos de pessoas indignadas que tomando as praças, ali instalaram suas "moradias" temporárias.

A propósito da inundação parisiense de 1955, e retomando Barthes (2009, p. 63), é possível referir que

[...] essa perturbação não é visualmente ameaçadora

[...]: a apropriação do espaço foi suspensa, a percepção está abalada, mas a sensação global permanece agradável, 
pacífica, imóvel e afável; o olhar é levado a uma diluição infinita; a ruptura do visual cotidiano não é da ordem do tumulto: é uma mutação de que não se vê senão o caráter consumado, o que afasta seu horror.

Tal como na inundação de Paris, essa mutação do espaço público das praças europeias e africanas não é, na maioria dos casos, do domínio da catástrofe ou da ameaça como as turbas violentas e amotinadas do final século XIX e meados de século XX na Europa industrial; ela é essencialmente pensada como produtora de uma nova existência, de uma nova vivência, onde os sujeitos que dela emergem se podem assumir como verdadeiras personae de uma perfomance política em fabricação. Personae porque nem apenas pessoas com biografias cotidianas, nem apenas actores em representação dramática, mas algures in-between. E tal como na descrição da inundação, em que "[...] vaise de barco ao armazém, o padre entra de barco em sua igreja, uma família vai às compras de canoa [...]" (Barthes, 2009, p. 64), também, na praça habitada pelos indignados, os itinerários rotineiros se veem confundidos pela interrupção performativa do acampamento, pela intersticialidade de um espaço simultaneamente novo e conhecido. E tal como na Paris inundada

[...] a essa espécie de desafio acrescenta-se a euforia de reconstruir a cidade ou o bairro, de dar-lhe caminhos novos, de utilizá-lo um pouco como um lugar teatral. [...] Fato paradoxal, a inundação fez um mundo mais disponível, manejável, como a espécie de deleite que a criança sente ao arrumar seus brinquedos, ao explorá-los e ao brincar com eles. (Barthes, 2009, p. 64-65)

Nas praças de Madrid, Barcelona, Atenas, Londres ou Lisboa, criaram-se espaços diversificados - lugares de leitura e de estudo (porque havia muitos estudantes envolvidos) e oficinas de vários assuntos (da permacultura à desbediência civil, da reciclagem à alimentação sustentável), cozinhas improvisadas, espaços de lazer e reposo ou de actividades físicas e espirituais (massagens, yoga, meditação), de acesso à internet, entre outras.

A praça adquire, portanto, novos significados, a sua paisagem e o seu território assumem outros sentidos, e é agora habitada por 
aqueles que se querem tornar espectadores emancipados - para usar a metáfora de Jacques Rancière (2010) - do teatro político. Essa declaração performativa sob a forma de acampamento que reclama o direito a reocupar o espaço público como espaço de construção da esfera pública, do debate político e da produção de democracia, é mais do que um acto simbólico - ela pretende produzir realidade! Como as performative utterances ou os speech acts de J. Austin e J. Searle que não apenas enunciam, mas são e fazem algo, também essa nova paisagem da praça é e faz algo. Tal como Rancière sublinhava para a arte performativa contemporânea, essas perfomances políticas contemporâneas

[...] exigem dos espectadores que desempenhem o papel de intérpretes activos, que elaborem a sua própria tradução para se apropriarem da "história" e dela fazerem a sua própria história. Uma comunidade emancipada é uma comunidade de contadores e tradutores. (Rancière, 2010, p. 35)

Essa dupla dimensão performática - por um lado, de espectadores emancipados e, por outro, de cenários que produzem atos - é também produtora de relações de tensão, numa visão binária do espaço público convencionado. O modelo de divisão dualista do espaço urbano - o da possibilidade e aquele da impossibilidade, o do puro e do impuro, o do consagrado e o do não consagrado, o do poder e o da subordinação, o da representatividade e o da delegação, e até o das divisões classistas enter ricos e pobres - é posto em causa nesses movimentos sociais que tomam as praças. Reclama-se agora uma cidade sem muros, uma cidade desafiando voltar a fazer da política uma coisa pública, em praça pública. E então esse tem sido o aspecto mais duramente reprimido em todos os países europeus: cargas policiais sobre acampados ocorreram desde maio de 2011, em Lisboa 6 , em Madrid, Atenas, Bruxelas, Paris, Barcelona, Valência, Ibiza, Londres, Berlim, entre outras, apesar do carácter maioritariamente pacífico desses protestos. A perceção dos Estados e dos seus aparelhos policiais de que existe uma perigosidade ameaçadora na habitação festiva e performativa dos espaços públicos mais simbólicos das suas cidades, é também a demonstração da agência dessas manifestações públicas. E revela, dessa forma, que elas não pretendem ser figurativas ou simbólicas apenas, mas ser algo de 
fato e produzir atos, criando vida, tornando-se vivência - e não mera teatralidade ilusória (como em amplo sentido o é o dissenso político parlamentar, por exemplo).

A praça habitada por novos sujeitos torna-se finalmente um lugar de liminariedade em que público e privado se confundem performativamente, em que intimidade e estranheza possam conviver e que insiders e outsiders se misturam. A praça é de todos, reclama-se em cada lugar, recorrendo aos artigos constitucionais de cada país para salvaguardar o imperativo democrático do direito de livre expressão. O Estado responde com a argumentação ligada à perturbação da ordem pública, à penalização turística dos centros históricos ocupados, aos imperativos da higiêne pública - ou, quando não suficientes ou credíveis esses argumentos, através da infiltração de agents provocateurs para instigar e gerar violência. A praça torna-se não o lugar caótico em que o poder cai na rua, mas o lugar onde o poder se constrói na rua, ameaçando por esse ato performativo em plenários e em rituais cotidianos de domesticidade do espaço público, a redifinição da esfera pública contemporânea. Como o rio que deixa de ser rio na inundação para passar a ser um horizonte único, uma coisa em si, em que novas formas de relação se exigem e se vivem.

A praça destituída temporariamente dos seus significados históricos, monumentais, patrimoniais, culturais, econômicos e políticos é, em certo sentido, a marca que se pretende estabelecer no território urbano de um novo modo de pensar e de agir: ou seja, o que os manifestantes reclamam por democracia verdadeira, direta ou real. Seguramente, um desejo talvez utópico e efémero que importa entender melhor, sobretudo nos contornos que decorreram das variações de contexto para contexto de ocupação, na emergência de lideranças "de rua", na interferência colaborativa ou infiltrada de partidos e organziações sindicais nesses porcessos, na urgência de criar respostas ao capitalismo neoliberal que resultou na experimentação de forcings ideológicos tradicionais, na multiplicidade de coletivos e na precaridade de consensos alargados, na dominação dos meios de informação produzidos por estes movimentos e na rotatividade dos "porta-vozes", e obviamente, na continuidade de protestos de naturezas mais tradicio- 
nais oriundas de partidos e de sindicatos que se mantêm obviamente ativos, entre outros fenômenos que podem ser avaliados.

No entanto, a "rua", como espaço público nas cidades modernas, tem sido, sobretudo, pensada como o lugar para a mobilidade transeunte, para o flâneur turístico ou para certas actividades comerciais, uma espécie de "teatro direcionado" como refere Schechner (1995). A rua como espaço de celebração está se tornando objecto de profunda regulação e regulamentação. O caso do Brasil é absolutamente sintomático disso mesmo, com um conjunto de medidas restritivas, por exemplo, à manifestação artística (entendida como mendicidade ou venda não regulada pelos poderes municipais). Também a venda ambulante (camelô) tem sido objecto de inúmeras regulações e restrições, havendo mesmo exemplos recentes de tumultos e motins urbanos na América Latina por essas mesmas razões. E não deixa de ser curioso que uma das situações que espoletou a revolta no mundo árabe tenha sido a aplicação de medidas restritivas a um vendedor de rua tunisino que acabou por se imolar.

A regulação e vigilância da actividade comercial ambulante nas sociedades contemporâneas tem sido entregue aos espaços comerciais oficiais e institucionais (centros comerciais e mercados) e, cada vez mais, os eventos festivos se encontram institucionalizados sob a forma de festivais, concertos, exposições ou atividades lúdicas promovidas pelas muncipalidades ou pelo poder nacional, pelo que os momentos de desregulação do espaço público são problemáticos ainda que tenham respostas diversas por parte das autoridades instituidas. Uma dessas perfomances desreguladores têm sido as manifestações políticas de movimentos sociais, por exemplo, as enormes manifestações estudantis na China na Praça Tianamen em que o teatro estudantil se confrontava com o ritual de Estado - como refere uma vez mais Schechner (1995), ainda que sublinhe o carácter fluído e intercomunicável entre teatro e ritual. Sugere-se aqui uma leitura um pouco mais complexa para a interpretação destes (novíssimos) movimentos sociais contemporâneos: uma complexificação que introduz a perfomance, no sentido mais pleno do termo - isto é, como vivência (liveness). Essas mobilizações que tomam a rua, e ali se tornam mais ou menos perenes, emergem 
não apenas como teatros de rebelião que confrontam espaços rituais do poder oficial, mas como perfomances que fazem os seus atores/sujeitos virar personae (not-not-me para usar de novo a linguagem de Schechner). Ou seja, não se trata aqui, em meu entender, de construir apenas uma narrativa da insurreição pública em modo subjuntivo (as if) mas de claramente instaurar uma experiência e um fluxo vivencial. E, curiosamente, em Pequim os estudantes também decidiram acampar na Praça até serem esmagados pelo massacre militar de 3 e 4 de junho de 1989, talvez, por isso, Schechner veja nele mais um teatro direto. Ele não é tanto "sobre" algo, mas é mais "feito de" alguma coisa.

\section{Conclusões: a rua como um lugar heterotópico para espectadores emancipados}

Na verdade, a "rua", ou melhor, "estar na rua" para além de ser objeto de legislação e de vigilância apertada pelas autoridades em todo o mundo, é também, pelo menos em contexto europeu, pensada como o lugar de grupos excluídos, marginais ou liminares - prostitutas, vagabundos, mendigos, "nômades" e imigrantes, sobretudo ilegais. Essa estigmatização frequente do "estar na rua" obviamente se dilui parcialmente nas democracias aquando das concentrações ou manifestações de protesto, mas esse movimento "bizarro" de habitar a rua perenemente ou de ali deixar marcas relevantes - pontos de informação, cartazes, assembleias - é um fenômeno que emergiu nesses últimos meses por toda a Europa lançando outra forma de "democratizar a democracia", parafraseando o título do livro de Boaventura Sousa Santos (2002). A visibilidade desses protestos ao "tomarem as ruas e as praças" reclama ainda mais do que um mero tempo extraordinário ou uma antiestrutura ritual para usar a linguagem turneriana; ela é a instauração de um tempo outro, ela é já em si um lugar - heterotópi$\cos ^{7}$, no sentido que Foucult lhe dá. Não se trata apenas de uma festa que eclode no intervalo do tempo regular, ela é a festa que instaura uma nova vivência. Não é um mero drama social, é uma cisma declarada que exige novas formas de cidadania e que experimenta in actu novas formas de cidadania. Mas tal como a inundação parisiense da descrição de Barthes, trata-se de uma ruptura da paisagem urbana 
que não brota da violência, nem assenta no terror. A praça ocupada torna-se habitada.

Zygmunt Bauman (2011), num artigo recente ao Corriere della Sera sobre os motins em Inglaterra, refere um espécie de distinção latente entre surtos revolucionários sem objectivos definidos do tipo destas insurreições violentas e os propósitos dos movimentos sociais atrás descritos. E ainda que ambos possam ter uma origem comum associada à perda de intervenção e agência na sociedade, seja ao nível do consumo, seja ao nível da participação cívica, a sua propagação e finalidades seguem rumos distintos. Usando a metáfora bélica do campo minado, diz-nos Bauman que as sociedades contemporâneas assistem a níveis de tensão assentes nas desigualdades sociais de qualquer tipo - fundamentalmente na divisão (historicamente contextualizada) entre quem tem e quem não tem certos objectos. Essa mesma aproximação foi pensada por Canclini (1999) ao sugerir que a luta cidadã pelo acesso ao consumo e à defesa de direitos de consumo era um dos aspetos novos nos movimentos sociais atuais. Mas com a criação de necessidades e de objetos para serem possuidos aumentou também exponencialmente o mal-estar, a humilhação, a raiva, o impulso da destruição, a pilhagem e o roubo. Tambiah (1996) havia já se referido à crônica criação de ciclos e padrões endémicos de violência no interior das sociedades democráticas. Bauman acrescenta que é o nível com que consumimos e nos livramos de objectos de consumo aquilo que determina os parâmetros fundamentais do nosso estatuto social e do sucesso. As lojas comerciais e a atividade de comprar/consumir viram mandamentos da vida contemporânea. Citando George Ritzer, Baumam (2011, p. 18) afirma que: “[...] os supermercados viraram nossas catedrais $[\ldots]$ " e acrescenta que "[...] a lista das compras virou nosso breviário, as procissões nos centros comerciais nossas peregrinações".

Esse enfoque sobre o indíviduo excluído dos lugares sagrados do consumo aparentemente fixaria bem o retrato dos autores das pilhagens em Inglaterra, que veriam nas lojas e cadeias de corporações transnacionais o lugar do inimigo - bastiões fortificados e vigiados que lhes barravam o acesso aos bens. A perfomance violenta e dirigida apenas em função dos heterógeneos interesses e desejos pessoais de pertencer 
ao mundo dos consumidores, assumiria assim uma, parece-me, clara distinção com as formas de mobilização social, descritas ao longo deste texto. Nas praças, o processo parece concorrer aprentemente para uma perfomance em que espectadores emancipados querem se apoderar da esfera pública para nela jogarem a construção dos seus direitos cívicos e políticos, e fazem-no de forma pacífica e à luz do dia, de modo aberto e visível, reclamando a transformação das "catedrais do poder político" em assembleia nas quais o sujeito anônimo biograficamente se expõe e se consubstâncía em persona; de outro modo, o pilhador amotinado, escondido pela opacidade nocturna e pela máscara teatral, performativamente violento, reclama e invade as "catedrais do consumo" e sacia, por instantes, a sua voracidade pelo objecto de consumo a que hipnotizadamente tem sido convidado como espectador passivo e acalma a humilhação do exílio sistemático a que é votado. Mas finalmente, um e outro, amotinados e indignados, são a face mais evidente do processo de desigualdade e exclusão social contemporânea e a manifestação da decomposição do capitalismo contemporâneo. Aquilo a que Noam Chomski aludiu, na sua conferência numa Praça de Boston a convite do movimento Occupy Boston, como sendo a divisão entre plutonomia e preciaridade e que ficou nitidamente traduzido e plasmado na já mítica alegoria do movimento Occupy: "We are the $99 \% .^{8}$ 
5 Assembleia do Rossio, Lisboa, 2011 (autoria das fotos: Paulo Raposo)

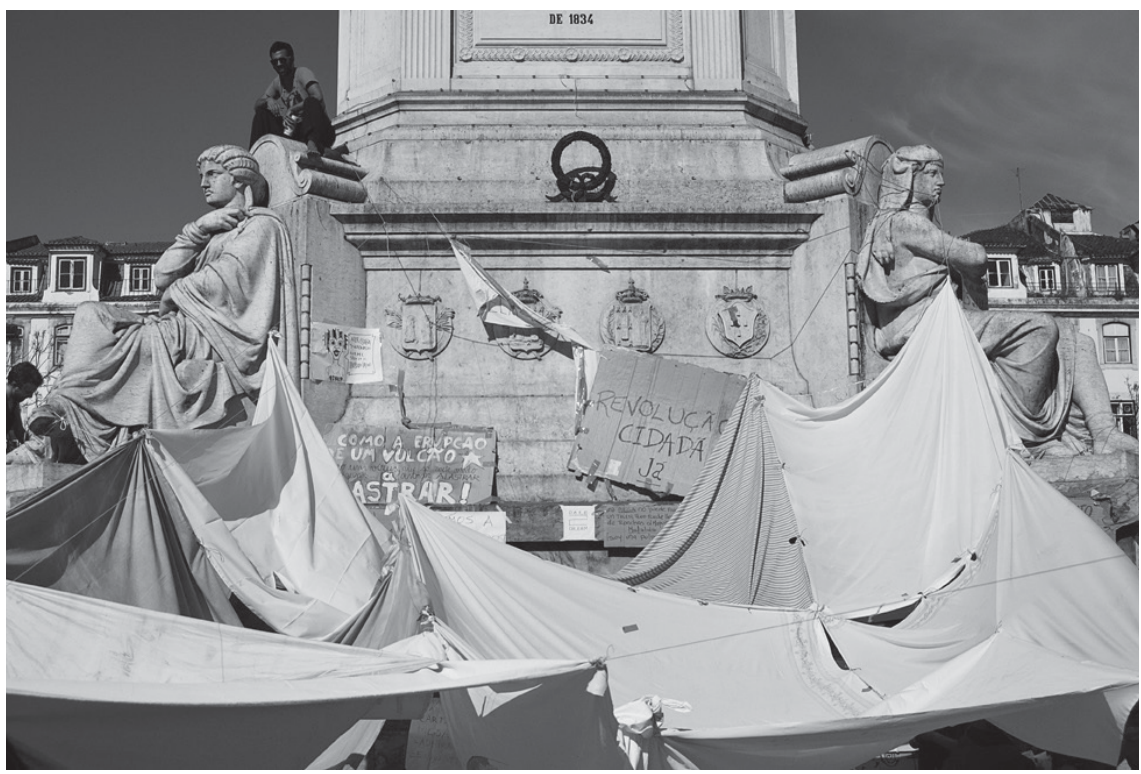

Foto 1: Montando acampada

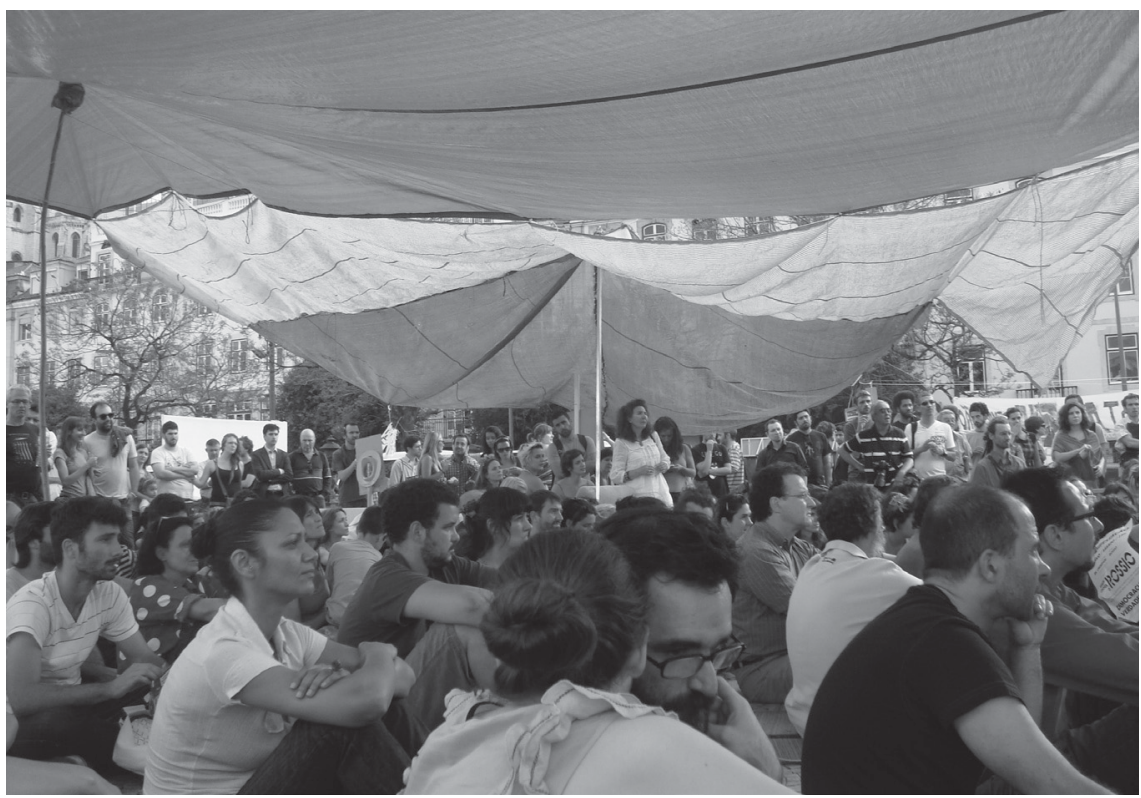

Foto 2: Assembleia 


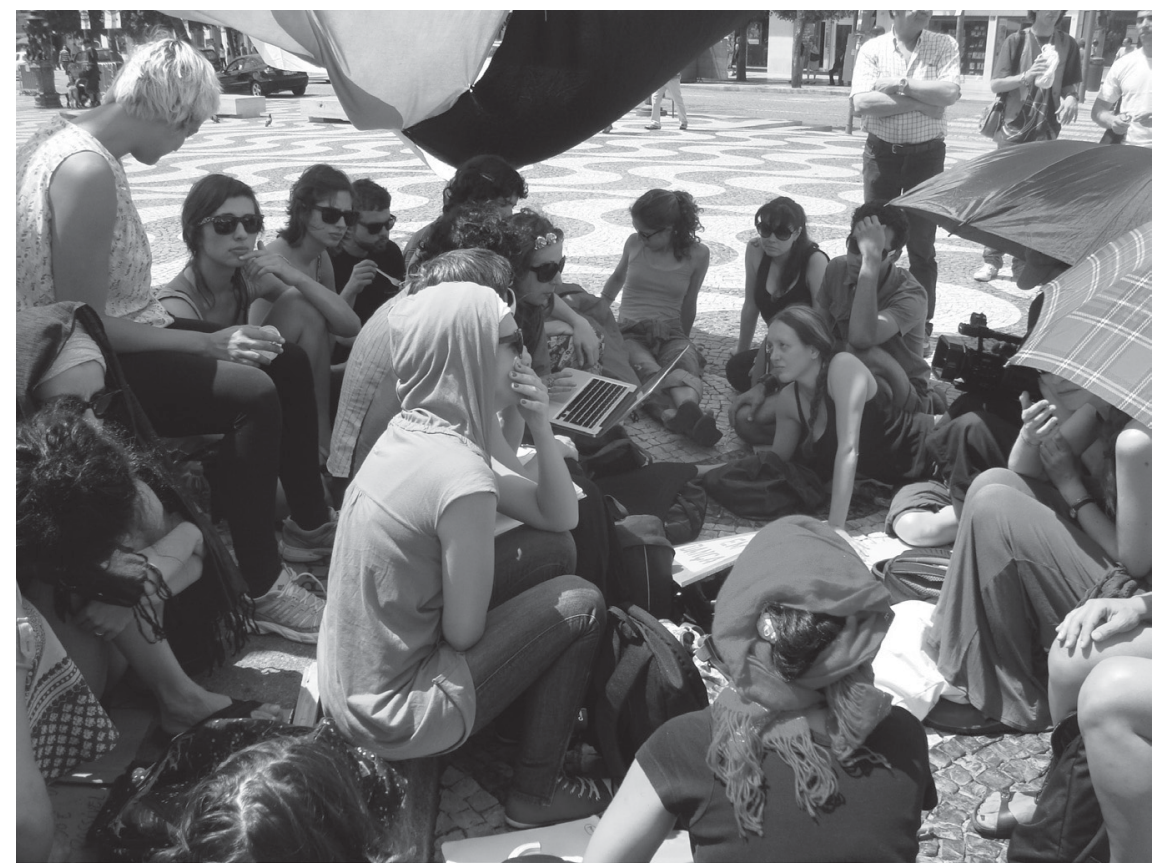

Foto 3: Grupo de trabalho

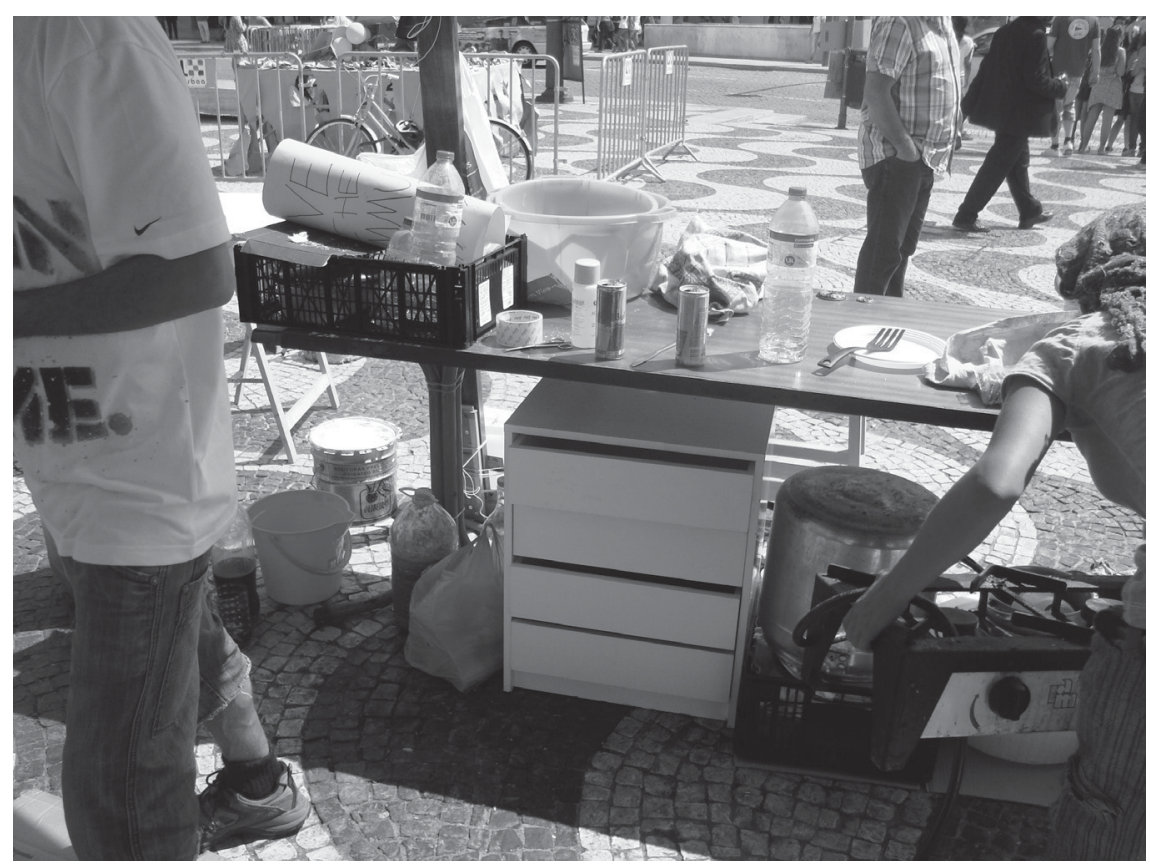

Foto 4: Cozinha da acampada 


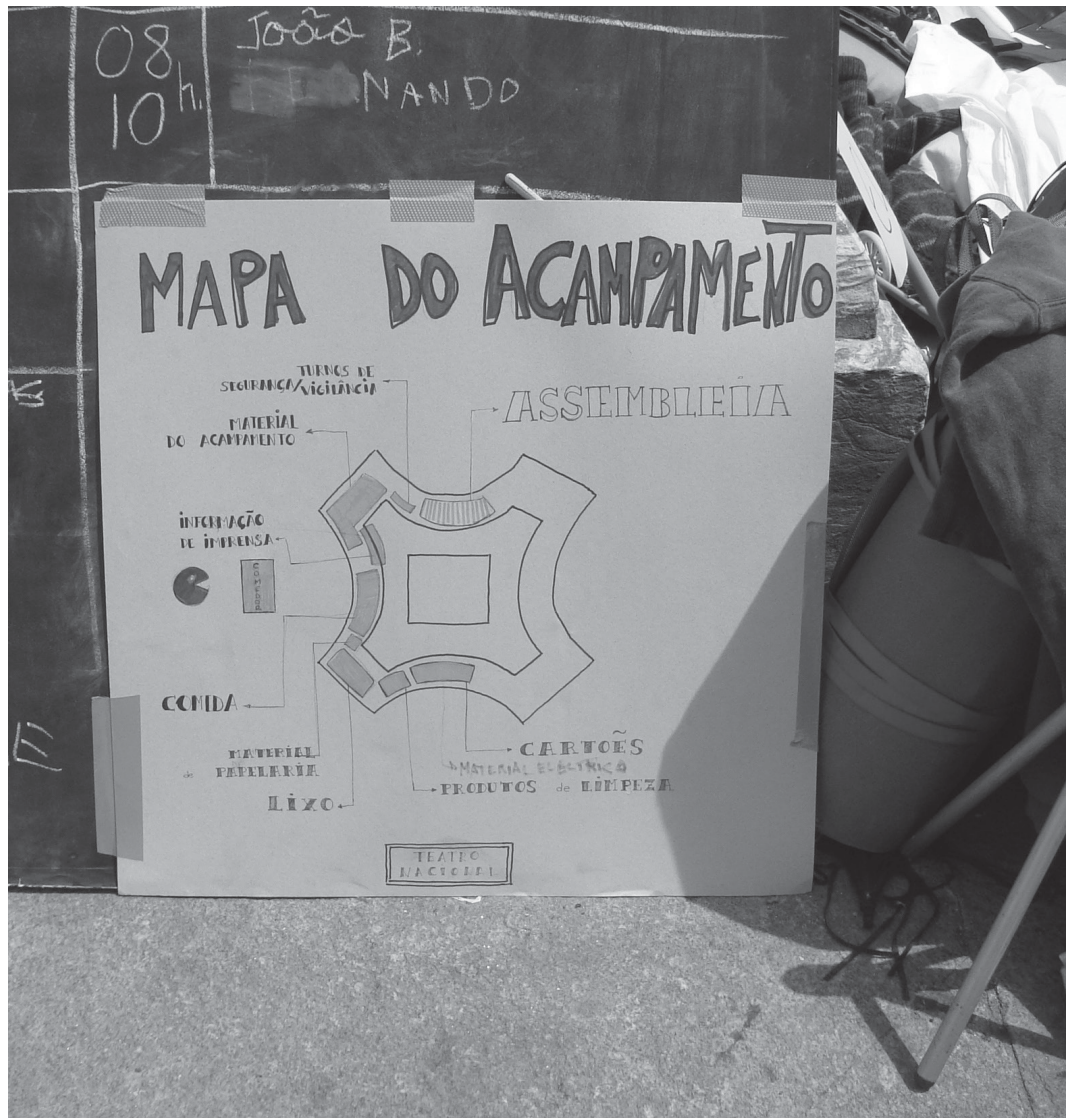

Foto 5: Mapa do acampamento

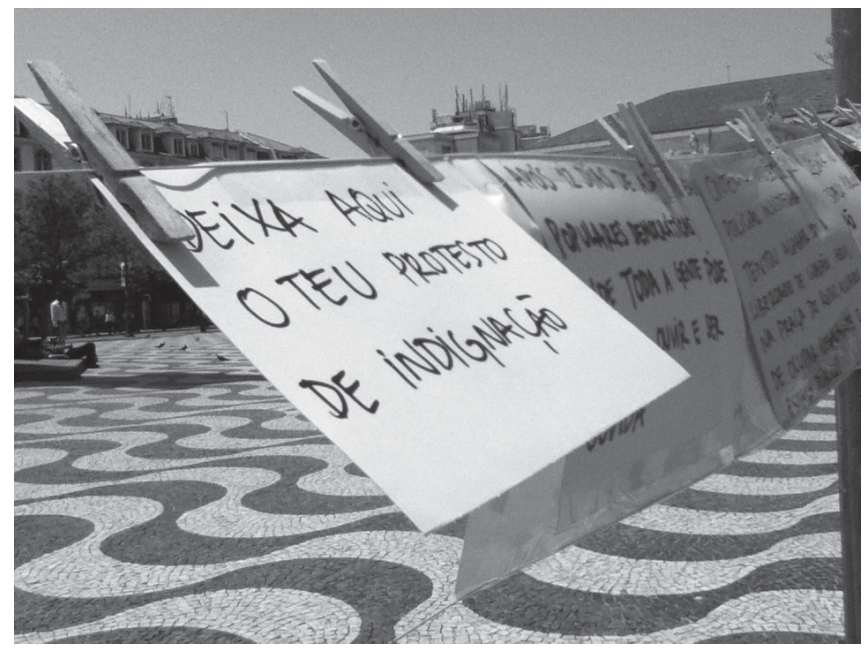

Foto 6: Exposição final na Praça do Rossio 


\section{Notas}

1 Este artigo resulta parcialmente da comunicação apresentada no Colóquio Internacional Festa e Sociabilidades em Belo Horizonte, em agosto de 2011, no painel coordenado por mim e pelo professor John Dawsey (USP-Napedra) a quem agradeço a leitura do texto naquele evento por impossibilidade de me deslocar. Agradeço ainda às sugestões críticas dos pareceristas deste artigo.

2 Mais reforça esta ideia pelas recentes posições de confronto declarado que países como a Argentina, o Brasil ou o Equador assumiram face ao pagamento das suas dívidas externas a entidades supranacionais como o FMI ou o Banco Mundial.

3 Na verdade, esse mal-estar social eu já vinha a sentir no Egito há alguns anos com manifestações pontuais muito reprimidas policialmente, sobretudo, quando do apoio à Intifada Palestiniana em 2000 e 2002 e após a invasão do Iraque em 2003, uma vez que Mubarak e o seu governo assumiram posicionamentos muito ambíguos nesses conflitos.

4 Este termo decorreu de uma polémica jornalística a propósito de uma ação direta estudantil realizada na década de 1990 na qual alguns jovens universitários exibiram o seu traseiro ao então ministro da educação pela subida dos preços de frequência do ensino superior. Nessa altura, em 1994, Vicente Jorge Silva, um jornalista com alguma notoriedade e de perfil conservador, publicou no jornal Público, um jornal de grande tiragem nacional, uma crônica de opinião com o título "geração rasca" (ou seja, decadente, mal-educada e de baixo estatuto) para se referir muito criticamente aos jovens ativistas (ver foto do protesto aqui: <http://jamandasnao. blogspot.pt/2009/06/quem-mostra-o-cu-tem-consciencia.html>, acesso em 10 de junho de 2011). Curisosamente, um desses jovens envolvidos naquela ação de protesto estudantil foi justamente, alguns anos mais tarde, um dos promotores da manifestação do dia 12 de março de 2011 que, fazendo uso de um trocadilho linguístico, se designou "geração à rasca" ou "enrascada".

5 Neste site: <http://www.youtube.com/watch?feature=player_embedded\&v=3DXJ0qPXrCA > está um dos vídeos de propaganda do movimento nos primeiros dias de manifestação, acesso em 10 julho de 2011; e ainda a página wikipédia criada pelo movimento: <http://es.wikipedia.org/wiki/\%C2\%AlDemocracia_Real_YA>, acesso em 10 de julho de 2011 . Existem depois vários websites, blogues e páginas de Facebook de réplicas locais do movimento, espalhadas por quase todas as cidades do Estado Espanhol, bem como de assembleias populares criadas nessas cidades.

6 No dia 4 de Junho de 2011 , uma carga policial que resultou ainda na detenção de 2 activistas da acampada do Rossio acabou destruindo uma exposição de cartazes, panfletos, fotos e materiais diversos produzidos durante a acampada e afixados na rua como memorial da presença assembliária naquela praça. Ver site da acampada mais informação: https://acampadalisboa.wordpress.com/category/repressao-policial/page/3/ acesso 10 de julho 2011

7 Heterotopia (aglutinação de hetero = outro + topia = espaço) foi um conceito elaborado pelo filósofo Michel Foucault que descreve lugares e espaços que funcionam em condições não hegemônicas. Foucault usa o termo heterotopia para descrever espaços que têm múltiplas camadas de significação ou de relações a outros lugares e cuja complexidade não pode ser vista imediatamente e diferenciam-se das utopias porque elas são apenas imagens, ideias e ideais, enquanto os lugares heterotópicos existem de fato. Foucault fornece alguns exemplos: navios, prisões e hospícios, motéis usados por amantes, gays ou solteiros em sociedades cujo sexo é vigiado e moralmente confinado a casais matrimoniais; museus que reunem o presente e o 
passado; templos e lugares sagrados; espelhos, livros e filmes de fição que criam ilusões entre real e virtual; jardins zoológicos e botânicos que recriam num local único habitats muito distintos, entre outros.

8 Veja-se a notícia da conferência em Boston neste períodico: <http://pe.globedia. com/noam-chomsky-ocupa-wall-street $>$, acesso em 12 de dezembro de 2011.

\section{Referências}

ABED, Mohammed/AFP/Getty Images, publicada na versão online do jornal inglês. The Guardian. 6 de junho de 2011 . Disponível em: < http:// www.theguardian.com/film/2011/jun/06/social-media-documentarymakers $>$. Acesso em: 10 jul. 2011.

ACAMPADA Lisboa. Foto sem autor, publicada no Blogue da Acampada do Rossio. 27 de maio de 2011 . Disponível em: < https://acampadalisboa. wordpress.com/category/manifestacao/page/3/>. Acesso em: 10 jul. 2011.

APRESENTAÇÃO do M12M - Movimento 12 de Março. 21 abril de 2011.

Disponível em: <http://geracaoenrascada.wordpress.com/201 1/04/21/ apresentacao-do-m12m-movimento-12-de-marco-2/>. Acesso em: 10 jul. 2011.

ARENDT, Hannah. A Condição humana. Lisboa: Relógio d'Água. 2001. (ed. original: The Human Condition, 1958)

BARTHES, Roland. Mitologias (tradução de Rita Buongermino). 4. ed. Rio de Janeiro: Difel. 2009. (ed. original: Mytologiques, 1957)

BAUMAN, Zygmunt. Quei figli umillitati del consumo all'assalto delle nuove cattedrali. Corrieri della Sera, 11 de agosto de 2011 , p. 18.

CANCLINI, Nestor García. Consumidores e cidadãos. Rio de Janeiro: Ed. UFRJ. 1999

CHEBIL, Mehdi. Fotojornalista. Revolution Rewinded - Egypt.

November 2011 - Clashes between police and anti-government protesters near Tahrir square. Disponível em: < http://www.chebilink.com/>. Acesso em: 10 jul. 2011.

DA MAIA NOGUEIRA. Publicada no Blogue da Acampada

Lisboa. 8 de junho de 2011. Disponível em: <https://

picasaweb.google.com/102847997171588898632/

Exposicao4JRossioDaMaiaNogueira\#5615873597720505554 >. Acesso em:

10 jul. 2013.

DA MAIA NOGUEIRA. Publicada em Blogue da Acampada

Rossio. 8 de junho de 2011. Disponível em: < https://

picasaweb.google.com/102847997171588898632/

Exposicao4JRossioDaMaiaNogueira\#5615873767522615986>. Acesso em: 10 jul. 2011. 
DOWNING, John. Mídia Radical: Rebeldia nas comunicações e movimentos sociais (tradução Silvana Vieira). São Paulo: Senac. 2002. (ed. original: Radical Mídia: Rebellious Communication and Social Movements, 2001)

ESCOBAR, Arturo. Culture, Pratices and Politicis: anthropology and the study of social movements. Critique of Anthropology, v. 12, n. 4, p. 395 435, Londres, 1992.

ESPANHA - 15 M: redes e assembleias. Foto sem autor/Reuters, publicada em 6 de junho de 2011. Disponível em: < (http://paginaglobal.blogspot. pt/201 1/06/espanha-15-m-redes-e-assembleias.html $>$. Acesso em: 10 jul. 2011.

GOHN, Maria da Glória. Movimentos sociais na contemporaneidade.

Revista Brasileira de Educação, Rio de Janeiro, v. 16, n. 47, maio-ago, p. 333-361, 2011.

INNERARITY, Daniel. O Novo espaço público. Tradução Manuel Ruas. Lisboa: Teorema. 2010. (ed. original: El Nuevo Espacio Público, 2006)

KOLESIDIS, John/Reuters. In Pictures: Rage in Athens. Publicado em Al Jazeera, 2 de julho de 201 l. Disponível em: < http://www.aljazeera.com/ indepth/features/2011/07/20117117719345898.html>. Acesso em: 10 jul. 2012.

KOLESIDIS, John/Reuters. Publicada em The Guardian em 24 de junho de 2011. Disponível em: <http://www.theguardian.com/business/2011/jun/24/ credit-default-swap-insurance-may-be-worthless $>$. Acesso em: 10 jul. 2011.

PICTURES of the day: 7 February, 2011. Foto sem autor e publicada em The Telegraph. 2011. Disponível em: < http://www.telegraph.co.uk/ news/picturegalleries/picturesoftheday/8308275/Pictures-of-the-day-7February-2011.html?image $=12>$. Acesso em: 10 jul. 2011.

POPULAR assembly at the occupied Syntagma Square in Athens, in 2011. Foto sem autor, publicada em 2011. Disponível em: < http:// occupywallstreet.net/story/what-would-real-democracy-look $>$. Acesso em: 10 jul. 2011.

RANCIÈRE, Jacques. O Espectador emancipado. Tradução José Miranda Justo. Lisboa: Orfeu Negro. 2010. (ed. original: Le spectateur emancipé, 2009)

RIOT police break up Barcelona protest as May 15 rallies take place across Spain. [2011]. Foto sem autor/Reuteurs publicada pelo The Telegraph. Disponível em: <http://www.telegraph.co.uk/news/picturegalleries/ worldnews/8541491/Riot-police-break-up-Barcelona-protest-as-May-15rallies-take-place-across-Spain.html?image $=1>$. Acesso em: 10 jul. 2011 . 
SANTOS, Boaventura de Sousa (Org.). Democratizar a democracia: os caminhos da democracia participativa. Porto: Edições Afrontamento. 2002. SCHECHNER, Richard. The Future of ritual. New York: Routledge. 1995.

SOURCE, Paul White: AP; Publicado no Daily Telegraph. 20 de junho de 2011. Disponível em: <http://www.dailytelegraph.com.au/protesters-floodmadrid/story-fn6elm7z-1226078199007>. Acesso em: 10 jul. 2011.

TOURAINE, Alain. O Retorno do Actor: ensaio sobre sociologia. Lisboa: Piaget. 1996. (ed. original: Le retour de l'acteur, 1984)

TRUEBA, Felipe. Agência Efe. Cairo, Praça Tahrir e as comemorações da queda do regime de Mubarak. Foto publicada na Folha de São Paulo no dia 11 de fevereiro de 2011. Disponível em: < http://fotografia. folha.uol.com.br/galerias/2138-hosni-mubarak-renuncia-apos-18-dias-deprotestos $>$. Acesso em: 10 jul. 2011.

TURNER, Victor W. The Ritual Process: structure and anti-structure. Chicago: Aldine Publishing Company. 1969.

Recebido em 16/10/2014

Aceito em 1\%/11/2014 